\title{
Prognostic significance of the Musashi-2 (MSI2) gene in childhood acute lymphoblastic leukemia
}

\author{
H. Z. ZHAO, M. JIA , Z. B. LUO, Y. P. CHENG, X. J. XU, J. Y. ZHANG, S. S. LI, Y. M. TANG*
}

Division of Hematology-oncology, Children's Hospital of Zhejiang University School of Medicine, Key Laboratory of Reproductive Genetics (Zhejiang University), Ministry of Education, Yan-an Street, Hangzhou 310003, PR CHINA

${ }^{*}$ Correspondence: Y_M_TANG@zju.edu.cn

${ }^{*}$ Contributed equally to this work.

Received April 28, 2015 / Accepted August 24, 2015

\begin{abstract}
The prognostic value of the Musashi-2 (MSI2) gene has not yet been studied in childhood acute lymphoblastic leukemia (ALL). In our study, MSI2 mRNA levels of 119 childhood patients with newly-diagnosed ALL were examined and analyzed with regard to clinical characteristics and outcomes. ALL patients demonstrated significantly higher MSI2 mRNA levels than healthy controls. In addition, MSI2 mRNA levels were correlated with the disease status and IK6 mutation status. Survival analyses showed that higher MSI2 mRNA levels predicted worse outcomes in patients with childhood ALL. Moreover, in multivariate analyses, MSI2 mRNA overexpression retained its value as an independent risk factor for overall survival (OS), but not for event free survival (EFS). We conclude that high MSI2 mRNA level predicts adverse prognosis and seems to be useful as a novel prognostic factor for patients with childhood ALL.
\end{abstract}

Key words: acute lymphoblastic leukemia, childhood, musashi-2, overall survival, prognosis

As the most common malignancy in pediatric population, acute lymphoblastic leukemia (ALL) is a malignant clonal proliferation disease of lymphoid progenitor cells [1]. One important feature of the disease is the acquired chromosomal and genetic abnormalities in the leukemic cells [2]. Together with other disease features such as age, white blood cell (WBC) counts and immunophenotype, some aberrations, like $B C R$ / $A B L 1$ and $M L L$ translocations, have been used as risk factors which can affect patients' treatment protocols and outcomes [3]. With the advances in the frontline protocols design, survival rates for childhood ALL have been improved over the past four decades [4]. However, 6-10\% of children with ALL have disease relapse. Thus, understanding the underlying novel genetic aberrations for refractory ALL is essential to discriminate patients with worse outcome and ultimately individualize treatment.

One of the major steps in leukemogenesis is the deregulation of the hematopoietic stem cells (HSCs) [5]. Being a member of an evolutionarily conserved family of RNA binding proteins, Musashi-2 (MSI2) serves as a regulator of HSCs and is primarily expressed in HSCs $[6,7]$. The results of mouse models of chronic myeloid leukemia (CML) show that through Musashi-Numb pathway, high levels of MSI2 play an important role in CML disease progression [7]. Just as MSI1 is a risk factor in gallbladder adenocarcinoma, astrocytic, oligodendroglial brain tumors, and breast cancer $[8,9]$, several studies have explored the role of MSI2 in hematological malignancies. MSI2 overexpression has been found to be an independent prognostic factor for both acute myeloid leukemia (AML) $[5,10]$ and adult $B C R / A B L$-negative $\mathrm{B}$-ALL $[11,12]$ and is associated with poor outcome. In addition, increased MSI2 expression is also found in advance disease (AD) CML patients [13].

However, the role of MSI2 in childhood ALL has not been evaluated. In this study, we analyzed the MSI2 mRNA levels and its relationship to survival and prognosis in a group of childhood ALL patients, aiming to evaluate its prognostic potential as a risk factor in pediatric ALL patients.

\section{Patients and methods}

Patients. We analyzed bone marrow (BM) samples from 119 patients with newly diagnosed ALL and 36 healthy donors treated in the Division of Hematology-oncology, the Children's 
Hospital of Zhejiang University School of Medicine from 2007 to 2010. The diagnosis of ALL was established based on morphology (M), immunology (I), cytogenetics (C), according to Recommendations for diagnosis and treatment of acute lymphoblastic leukemia in childhood (3rd revised version) [14]. BCR/ABL1 fusion transcripts were analyzed at first diagnosis. Additionally, seventeen paired samples at diagnosis and at complete remission (CR) were also collected. Informed consents for laboratory analysis and cryopreservation of BM samples were obtained from parents or guardians. This study abode by the tenets of Declaration of Helsinki and was approved by the Institutional Local Review Board of Ethics.

According to the modified National Cancer Institute (NCI) criteria, low-risk (LR), intermediate risk (IR) and high-risk (HR) groups were defined according to the clinical biologic characteristics, and early response to prednisone [15]. All of these patients were treated by the NPCAC97 protocol. Briefly, the treatment regimen included 7 days of pre-phase treatment with prednisone and 4 weeks of induction therapy consisting of four drugs (vincristine, daunorubicin, L-asparaginase and dexamethasone) which were described elsewhere $[16,17]$.

RNA extraction and cDNA synthesis. BM samples were collected in heparinized glass tubes, and mononuclear cells were isolated by Ficoll gradient centrifugation. Using High Pure RNA Isolation Kit (Roche, Mannheim, Germany), total RNA was extracted from cryopreserved cells stored in liquid nitrogen. Samples were chosen based on the quality and quantity of RNA. Reverse transcription was performed using the ReverTra Ace qPCR RT Kit (Toyobo, Osaka, Japan). Briefly, $1 \mu \mathrm{g}$ of total RNA was added to a $10-\mu \mathrm{L}$ volume containing reverse transcriptase and the Primer Mix. The mixture was incubated at $37^{\circ} \mathrm{C}$ for $15 \mathrm{~min}$, followed by 5 $\min$ at $98^{\circ} \mathrm{C}$. Then the reacted solution was stored at $-20^{\circ} \mathrm{C}$ until ready to use.

Quantification of MSI2 mRNA levels and detection of the Ikaros 6 (IK6) variant. MSI2 mRNA levels were quantified using StepOnePlus ${ }^{\mathrm{TM}}$ Real-time PCR system (Applied Biosystems) according to the manufacturer's instructions, with co-amplification of the housekeeping gene GAPDH. The comparative cycle threshold (CT) method, described in the previous studies $[18,19]$, was used to determine the relative expression levels of $M S I 2$ to GAPDH, using the mean of $\triangle \mathrm{CT}$ from three replicates and expressed as $2^{\mu(\Delta C T)}(\triangle \mathrm{CT}=$ GAPDH - MSI2). The reaction mixture was performed in a final volume of $25 \mu \mathrm{L}$ containing $2 \mu \mathrm{L}$ cDNA, $12.5 \mu \mathrm{L}$ SYBR Green PCR Master Mix, $1 \mu \mathrm{L}$ of $M S I 2$ primers $(5 \mathrm{nmol} / \mathrm{mL}$ ) or $G A P D H$ primers. PCR conditions used an initial denaturation at $95^{\circ} \mathrm{C}$ for $1 \mathrm{~min}$ followed by 40 cycles of 15 seconds at $95^{\circ} \mathrm{C}$, 15 seconds at $55^{\circ} \mathrm{C}$ and 30 seconds at $72^{\circ} \mathrm{C}$. MSI2 and GAPDH primers had been described in the previous study [12].

Moreover, the IK6 variant of IKZFI gene was also examined by nested PCR with the use of primers previously described [20].

The sequences of primers for MSI2, GAPDH and IK6 were as follows:
MSI2-1: ACGACTCCCAGCACGACC; MSI2-2: GCCAGCTCAGTCCACCGATA

GAPDH-1: ATGGGGAAGGTGAAGGTCG; GAPDH-2: GGGTCATTGATGGCAACAATATC

IK6-E1: CTCTTCGCCCCCGAGGATCAGTCTT; IK6-E2: GAAGGCGGCAGTCCTTGTGCTTTTC

IK6-I1: CGAGGATCAGTCTTGGCCCCA; IK6-I2: GCAGCTGGTACCATCGGGCTGAT

Statistical analysis. To delineate distinct patient subgroups on the basis of MSI2 mRNA levels, patients with expression values greater than $75^{\text {th }}$ of all measurements were defined as the high MSI2 mRNA group. To compare the pretreatment clinical features between high MSI2 mRNA group and low MSI2 mRNA group, $\chi^{2}$ test and the nonparametric MannWhitney $U$ test were chosen for categorical and continuous variables, respectively. Student t-test for independent samples or paired samples Student t-test was chosen to perform mean comparisons between distinct groups.

Overall survival (OS) was measured from the date of diagnosis to death with any cause or last contact, and event free survival (EFS) was defined as the time from diagnosis to treatment failure, relapse, death, or last follow-up. The last follow-up time was September 30, 2014. Survival analysis was performed for only 108 childhood ALL patients (9 patients who received hematopoietic stem cell transplantation were excluded.). Survival curves were estimated by the KaplanMeier method, and $P$ values were calculated by the log-rank test. Prognostic factor analysis was performed by univariate analysis and variables with a $P$-value $<0.1$ in univariate analysis were entered into the Multivariable Proportional Hazards Model. The following covariates were included in the full model: MSI2 mRNA levels (high $v$ low), Age ( $\leq 1$ year, $\geq 10$ years $v 1-10$ years), WBC counts $\left(\geq 50 \times 10^{9} / \mathrm{L} v<50 \times 10^{9} / \mathrm{L}\right)$, BM blast ( $\geq$ median $v<$ median), Risk (high + intermediate $v$ low), peripheral blood (PB) blast ( $\geq$ median $v<$ median), Day 22 minimal residual disease (MRD) $(\geq 0.01 \% v<0.01 \%), B C R /$ $A B L 1$ (presence $v$ absence), and IK6 (mutated $v$ unmutated).

All analyses were performed using SPSS software package, version 17 (SPSS Inc, Chicago, IL), and a $P$ value $<0.05$ was considered to be statistically significant.

\section{Results}

Analysis of MSI2 mRNA levels in pediatric ALL patients and healthy donors. The characteristics of controls and patients were summarized in supplemental Table I. The median age of healthy controls in our study was 6 years (range, 1 to 14 years), and there was no difference in ages between the healthy controls and ALL patients $(P=0.501)$. We analyzed the MSI2 mRNA levels in 119 pre-treatment BM specimens with newly-diagnosed ALL and 36 healthy volunteers. Overall, normal controls showed lower MSI2 mRNA levels compared to ALL patients $(P=0.030$, Figure 1a).

In order to demonstrate whether the MSI2 mRNA levels were influenced by disease status, 17 paired BM samples 
were also collected and studied at diagnosis and at CR. Our results showed that there was significant reduction in the MSI2 mRNA levels at CR than those at initial diagnosis $(P<$ 0.001 , Figure 1b).

Association between MSI2 mRNA levels and clinical characteristics of childhood ALL patients. Baseline clinical

a

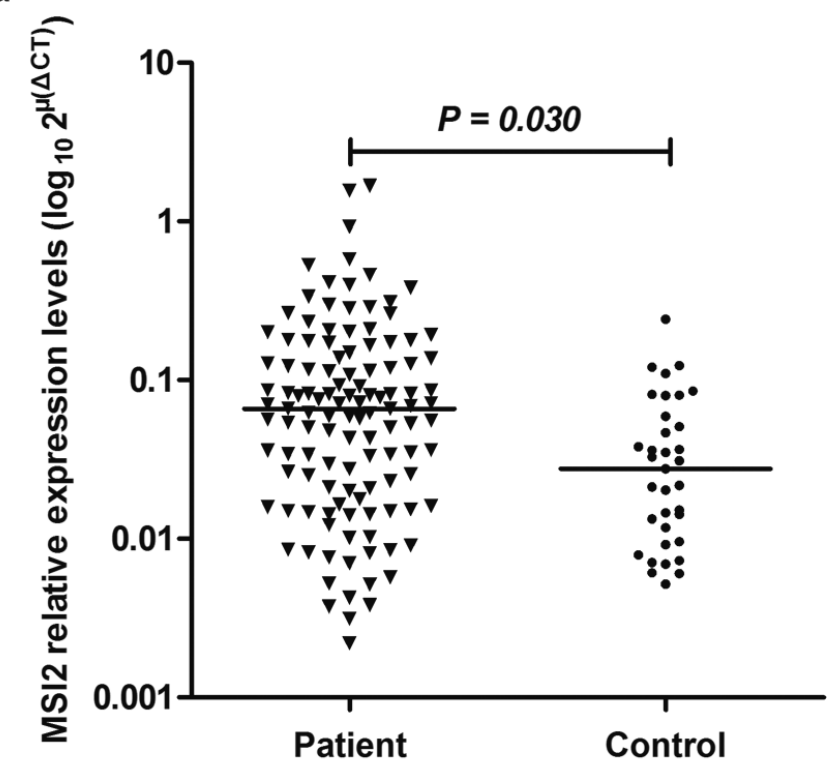

b

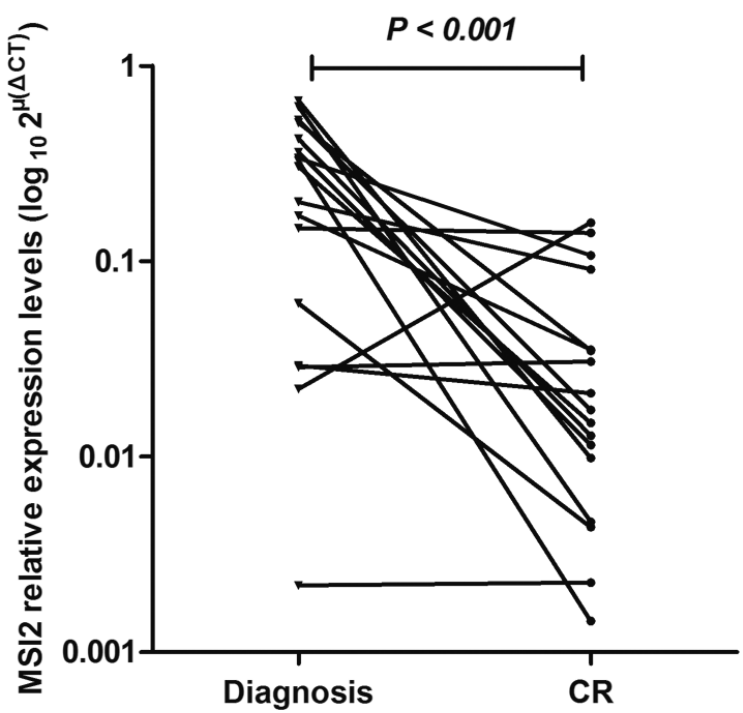

Figure 1. MSI2 mRNA levels in (a) pediatric ALL patients and healthy controls, and (b) 17 paired samples. (a) Independent-Samples $\mathrm{T}$ test and (b) Paired-Samples T test were used for the comparisons of MSI2 mRNA levels between two groups, using the $2^{\mu(\Delta \mathrm{CT})}$ values as MSI2 quantitative expression levels. For (a), the line showed the median value. The significant differences were observed in both (a) $P=0.030$ and (b) $P<0.001$. and molecular characteristics of the 119 patients enrolled in this study were summarized in Table I. When we compared the clinical and biological characteristics of the two subgroups classified on the basis of MSI2 mRNA levels, no significant difference was found for age, gender, WBC count, platelet (PLT) count, BM blasts, PB blasts, extramedullary involvement, immunophenotype, risk, $I K 6$, and $B C R / A B L 1$.

We then compared the MSI2 mRNA levels according to patients' molecular features, with the use of MSI2 mRNA expression values as a consecutive variable. Patients with IK6 mutation showed higher MSI2 mRNA levels compared to IK6 negative group $(P=0.0037$, Figure 2a). However, no such relationship was found between $B C R / A B L 1$ presence and absence groups $(P$ $=0.095$, Figure $2 b$ ).

Table I. Clinical characteristics of patients with high and low MSI2 mRNA levels

\begin{tabular}{|c|c|c|c|c|}
\hline Characteristics & $\begin{array}{l}\text { Patients } \\
(\mathrm{n}=119)\end{array}$ & $\begin{array}{c}\text { Low MSI2 } \\
(\mathrm{n}=89)\end{array}$ & $\begin{array}{l}\text { High MSI2 } \\
\quad(\mathrm{n}=30)\end{array}$ & $P$ \\
\hline Age, years & & & & .956 \\
\hline Median & 6 & 6 & 7.5 & \\
\hline Range & $1-14$ & $1-14$ & $1-14$ & \\
\hline Sex, male, no. (\%) & $76(64)$ & $57(64)$ & $19(63)$ & .994 \\
\hline WBC count, $x 10^{9} / \mathrm{L}$ & & & & .921 \\
\hline Median & 20.3 & 23.6 & 22 & \\
\hline Range & $0.8-760$ & $0.8-760$ & $2.4-552.9$ & \\
\hline PLT count, $x 10^{9} / \mathrm{L}$ & & & & .743 \\
\hline Median & 55.5 & 54 & 58.5 & \\
\hline Range & $4-359$ & $4-359$ & $13-339$ & \\
\hline Percentage of BM blasts & & & & .099 \\
\hline Median & $90 \%$ & $90 \%$ & $91 \%$ & \\
\hline Range & $61 \%-98 \%$ & $61 \%-98 \%$ & $70 \%-98 \%$ & \\
\hline Percentage of PB blasts & & & & .857 \\
\hline Median & $25 \%$ & $25 \%$ & $26 \%$ & \\
\hline Range & $0-85 \%$ & $0-80 \%$ & $0-85 \%$ & \\
\hline Extramedullary involveme & nt, no. (\%) & & & .992 \\
\hline Yes & $4(3)$ & $3(3)$ & $1(3)$ & \\
\hline No & $115(97)$ & $86(97)$ & $29(97)$ & \\
\hline Immunophenotype, no. (\% & & & & .306 \\
\hline B-ALL & $91(76)$ & $66(74)$ & $25(83)$ & \\
\hline T-ALL & $28(24)$ & $23(26)$ & $5(17)$ & \\
\hline Risk, no. (\%) & & & & .368 \\
\hline Low & $35(29)$ & $27(30)$ & $8(27)$ & \\
\hline Intermediate & $28(24)$ & $22(25)$ & $6(20)$ & \\
\hline High & $56(47)$ & $40(45)$ & $16(53)$ & \\
\hline Ik6, no. (\%) & & & & .133 \\
\hline Mutated & $13(11)$ & $7(8)$ & $6(20)$ & \\
\hline Unmutated & $106(89)$ & $82(92)$ & $24(80)$ & \\
\hline$B C R / A B L 1$, no. $(\%)$ & & & & .371 \\
\hline Presence & $11(9)$ & $7(8)$ & $4(13)$ & \\
\hline Absence & $108(91)$ & $82(92)$ & $26(87)$ & \\
\hline
\end{tabular}

Abbreviations: MSI2, Musashi-2; WBC, white blood cell; B-ALL, B-cell acute lymphoblastic leukemia; BM, bone marrow; Ik6, Ikaros isoform 6; PB, peripheral blood; PLT, platelet; T-ALL, T-cell acute lymphoblastic leukemia. 
Validation of MSI2 as a risk factor of outcome in pediatric ALL. In the entire cohort of patients, the low MSI2 mRNA group had significant higher CR rates compared with the high MSI2 mRNA group ( $97 \% v 83 \%, P=0.016$, Table II). However, no significant difference was found in the response to prednisone between the low MSI2 mRNA group and the high MSI2 mRNA group ( $88 \% v 79 \%, P=0.325$, Table II). Moreover, regarding to Day $22 \mathrm{MRD}$, no such association was found between the two groups defined based on MSI2 mRNA levels $(P=0.246$, Table II).

With a median follow-up time of 67.5 months $(1-93$ months), there were 108 ALL patients for OS analysis and EFS analysis. When we compared the OS of patients between the low MSI2 mRNA group and the high MSI2 mRNA group, the latter group of patients had inferior OS: high MSI2 mRNA expressers had lower estimated 5-year OS rate (60\% $v 81 \%$; median, $59 \vee 71$ months; $P=0.014$, Table II, Figure 3a). However, no statistical significance $(P=0.400$, Figure $3 b)$ was found between the estimated 5-year EFS rates for patients in the low MSI2 mRNA group and the high MSI2 mRNA group (67\% v60\%, respectively, Table II).

Validation of IK6 as a risk factor of outcome in pediatric ALL. We then investigated the association between IK6 mutation status and the outcomes in childhood ALL patients. The results from both EFS and OS showed that IK6 positive status was a poor prognostic factor in childhood ALL patients: 5-year EFS rate: $68 \% v 40 \%, P=0.010$; 5 -year OS rate: $80 \% v 42 \%$, $P=0.002$ (supplemental Figure 1).

Survival analysis based on IK6 mutation status and MSI2 mRNA levels in pediatric ALL patients. Based on the results described above, survival analyses were conducted among the four groups: MSI2hiIK6+, MSI2hiIK6-, MSI2loIK6+ and MSI2loIK6-. The 5-year OS rates were different among the four groups, which were $20 \%, 68 \%, 57 \%$, and $83 \%$ for MSI2hiIK6+,

Table II. Clinical outcomes according to MSI2 mRNA levels

\begin{tabular}{lcccc}
\hline Outcome & Patients & Low MSI2 & High MSI2 & $P$ \\
\hline $\begin{array}{l}\text { Day22 MRD } \\
\quad \text { >0.01\% (\%) }\end{array}$ & $65(62 \%)$ & $53(65 \%)$ & $12(52 \%)$ & \\
$\quad$ Response to prednisone & & & & 0.246 \\
$\quad$ Sensitive (\%) & $98(86 \%)$ & $76(88 \%)$ & $22(79 \%)$ & \\
CR & & & & 0.325 \\
$\quad$ Yes, no, (\%) & $110(94 \%)$ & $85(97 \%)$ & $25(83 \%)$ & \\
Overall survival & & & & 0.014 \\
$\quad$ Median, months & 68.5 & 71 & 59 & \\
$\quad$ Alive at 5-year, \% & 76 & 81 & 60 & \\
$\quad$ 95\% CI & $0.67-0.84$ & $0.72-0.90$ & $0.41-0.79$ & \\
Event-Free survival & & & & 0.400 \\
$\quad$ Median, months & 61.5 & 66 & 56 & \\
$\quad$ Relapse-free at 5-year, \% & 65 & 67 & 60 & \\
$\quad$ 95\% CI & $0.56-0.74$ & $0.57-0.77$ & $0.42-0.78$ & \\
\hline
\end{tabular}

Abbreviations: CI, confidence interval; CR, complete remission; MRD: minimal residual disease.
MSI2hiIK6-, MSI2loIK6+ and MSI2loIK6-, respectively ( $P$ $<0.001$, supplemental Figure 2a). Similar results were also observed for EFS analysis among the four groups $(P=0.005$, supplemental Figure 2b)

Multivariate analysis. MSI2 mRNA levels (high $v$ low) was still an independent prognostic factor of OS in multivariate

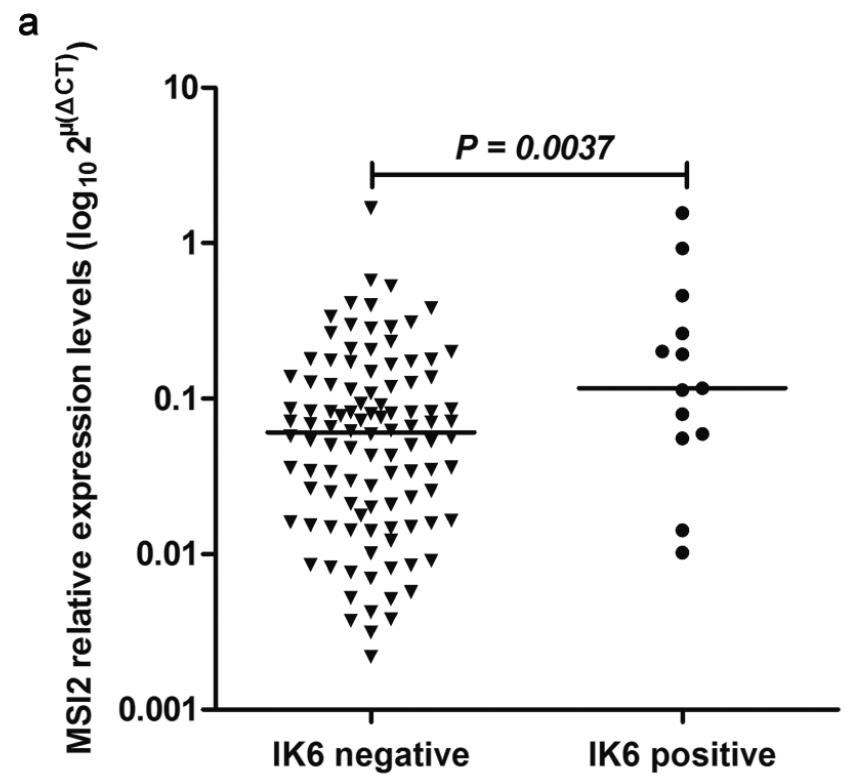

b

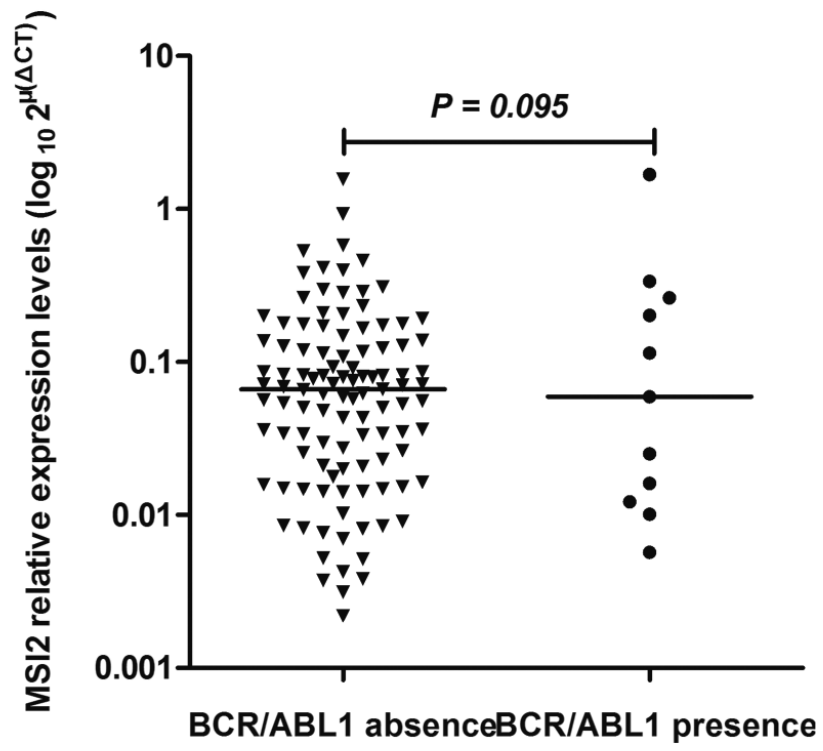

Figure 2. Differences in MSI2 mRNA levels according to genetic abnormalities status were studied. Independent-Samples $T$ test was chosen to test the differences between groups. MSI2 mRNA levels were estimated with the $2^{\mu(\Delta C T)}$ method, using GAPDH as the control gene. For (a) and (b), the line showed the median value. (a) A significant difference was observed between the IK6 mutation positive group and the $I K 6$ mutation negative group $(P=0.0037)$. (b) No statistical difference in MSI2 mRNA levels was found between the $B C R /$ $A B L 1$ absence group and the $B C R / A B L 1$ presence group $(P=0.095)$. 
analysis for ALL, when considering age, WBC counts, BM blast, risk, PB blast, Day22 MRD, BCR/ABL1 and IK6, (HR, 2.19; $95 \%$ CI, 1.03-4.67; $P=0.042$, Table III). Furthermore, BM blast ( $\geq$ median $v<$ median) and IK6 (mutated $v$ unmutated) were also prognostic predictors for OS (Table III). The independent prognostic factors for EFS were WBC counts

\section{a}

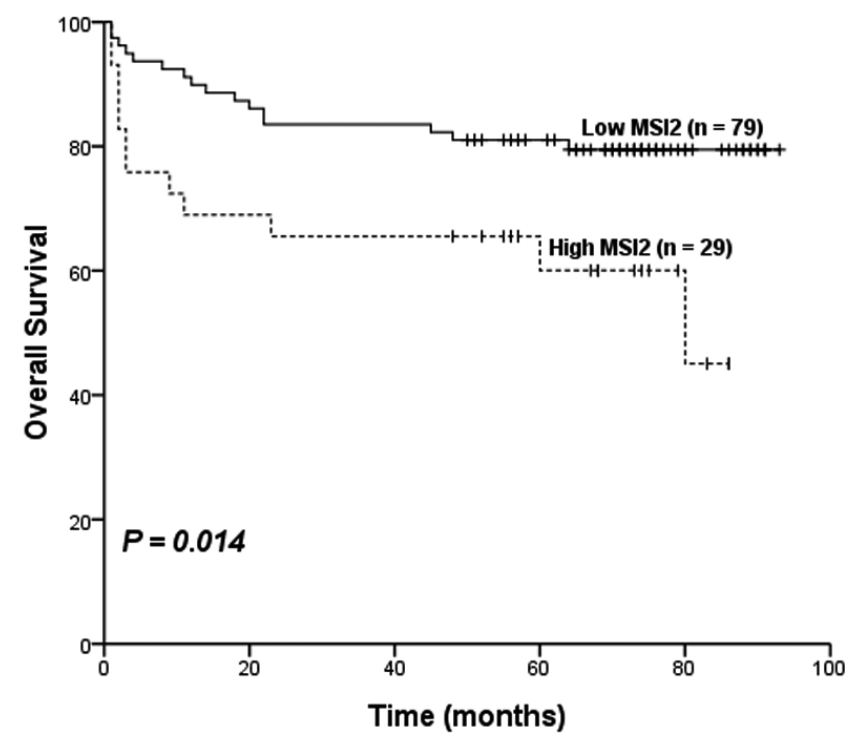

b

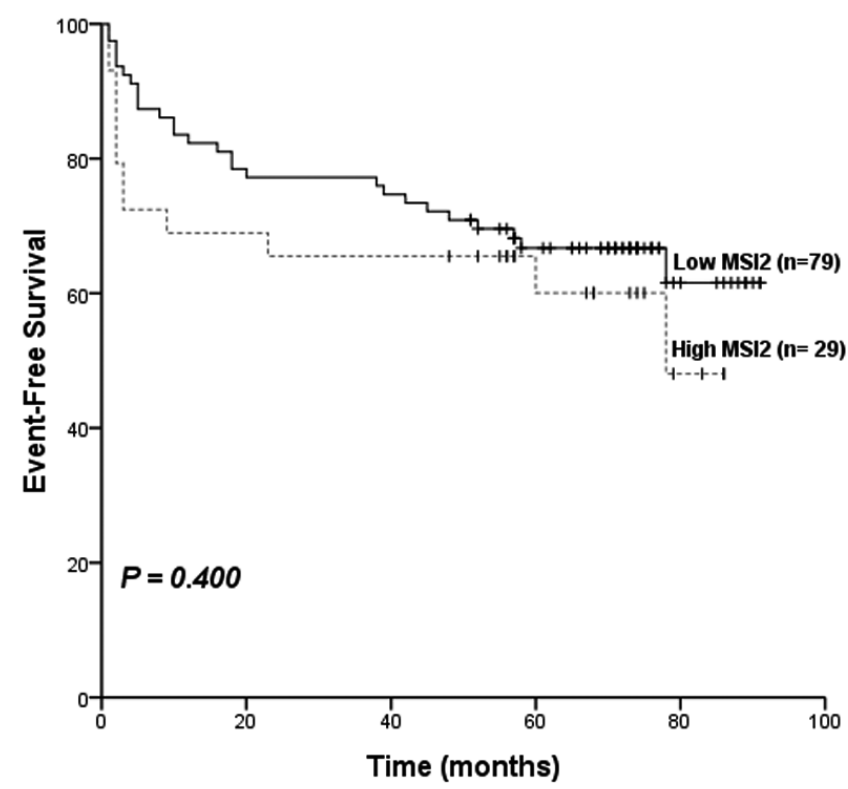

Figure 3. Influence of MSI2 mRNA levels on outcomes in childhood ALL patients. Patients with high MSI2 mRNA levels had inferior overall survival (OS) (a) $(P=0.014)$. Kaplan-Meier analysis demonstrated that estimated 5 -year OS rate for high MSI2 mRNA expressers was $60 \%$, whereas the estimated 5-year OS rate for low MSI2 mRNA expressers was $81 \%$. However, no difference in EFS was found between the high MSI2 mRNA group and low MSI2 mRNA group. $(b)(P=0.400)$. $\left(\geq 50 \times 10^{9} / \mathrm{L} v<50 \times 10^{9} / \mathrm{L}\right)$ and $B C R / A B L 1$ (presence $v$ absence) (Table III).

\section{Discussion}

The overall long time survival rates of childhood ALL are ranging from $70 \%-90 \%$ [21-23]. In spite of this, the fact that a small number of patients die or relapse during the treatment of diseases cannot be ignored. On the account of the important role which molecular signature plays in ALL riskstratification refinement and therapy development, we sought to evaluate the relationship between the MSI2 mRNA levels and ALL in the pediatric population. To our knowledge, this is the first study focusing on MSI2 mRNA levels in pediatric ALL patients.

Results from Ito T et al [6] show that MSI2 is important for the establishment and continued propagation of blast crisis for CML in animal models. Similarly, results from $151 \mathrm{CML}$ patients show that MSI2 levels increase during the advanced phases and decrease in chronic phases (CP) [13]. In this study, we investigated MSI2 mRNA levels in BM samples from newlydiagnosed ALL patients and compared those to the levels obtained from healthy donors. According to our results, MSI2 mRNA overexpression was detected in pediatric ALL patients. The result is consistent with the previous studies showing that the expression of MSI2 in AML patients and adults B-ALL is higher than in healthy volunteers $[12,24]$. However, the differences in MSI2 mRNA levels between healthy controls and ALL patients were not as large as expected. One reason may be the relatively small sample size. Further large-scale studies are in preparation and investigation. We then compared the MSI2 mRNA levels of paired samples collected at diagnosis and at CR, and the patients at CR showed significant lower MSI2 mRNA levels than at initial diagnosis. As compared to ALL patients at CR, patients at initial diagnosis had higher leukemia burden. Therefore, we can speculate that MSI2 mRNA overexpression may have an effect on outcomes of ALL patients in childhood population.

Ikaros is a central regulator of hematopoiesis, encoded by the IKZF1 gene. Due to alternative splicing or genomic deletions, the IKZF1 gene is transcribed as a number of isoforms [25]. One of the short isoforms is $I K 6$, with deletions in exon 4-7 of the IKZF1 gene [25]. Recent studies have demonstrated that deletions in IKZF1 are associated with unfavorable outcomes in pediatric B-ALL and adult B-ALL $[26,27]$. In our group, we have also verified that IK6 positivity was associated with poor outcomes in childhood ALL patients. Consequently, we aimed to evaluate the relevance between MSI2 mRNA levels and IK6 mutation status. As demonstrated in Figure 2a, patients with IK6 mutation showed higher MSI2 mRNA levels, as compared to IK6 negative group, suggesting that MSI2 mRNA overexpression may imply worse clinical features of childhood ALL. Similar to IK6, BCR/ABL1 is also an unfavorable prognostic factor for ALL, and is associated with older age, higher leukocyte count, and more frequent CNS involvement at time 
Table III. Multivariate analyses for OS and EFS in pediatric ALL patients

\begin{tabular}{|c|c|c|c|c|c|c|}
\hline \multirow[b]{2}{*}{ Factor } & \multicolumn{3}{|c|}{ OS } & \multicolumn{3}{|c|}{ EFS } \\
\hline & HR & $95 \% \mathrm{CI}$ & $P$ & HR & $95 \% \mathrm{CI}$ & $P$ \\
\hline Age, $\leq 1$ year, $\geq 10$ years $v 1-10$ years & 1.38 & $0.65-2.93$ & 0.396 & 1.44 & $0.76-2.72$ & 0.259 \\
\hline $\mathrm{WBC}, \geq 50 \times 10^{9} / \mathrm{L} v<50 \times 10^{9} / \mathrm{L}$ & 1.50 & $0.53-4.22$ & 0.094 & 2.58 & $1.34-4.96$ & 0.005 \\
\hline Risk, high + intermediate $v$ low & 1.23 & $0.4-3.81$ & 0.221 & 1.56 & $0.57-4.28$ & 0.385 \\
\hline MSI2 mRNA levels, high $v$ low & 2.19 & $1.03-4.67$ & 0.042 & 1.38 & $0.70-2.72$ & 0.358 \\
\hline BM blast $\%, \geq$ median $v<$ median & 2.51 & $1.05-5.97$ & 0.038 & 1.69 & $0.84-3.40$ & 0.130 \\
\hline PB blast $\%, \geq$ median $v<$ median & 1.36 & $0.48-3.86$ & 0.159 & 1.27 & $0.49-3.27$ & 0.393 \\
\hline Day $22 \mathrm{MRD}, \geq 0.01 \% v<0.01 \%$ & 1.53 & $0.58-4.03$ & 0.389 & 1.43 & $0.67-3.06$ & 0.353 \\
\hline IK6, mutated $v$ unmutated & 4.60 & $1.9-11.4$ & 0.001 & 2.01 & $0.83-4.87$ & 0.086 \\
\hline$B C R / A B L$, presence $v$ absence & 1.89 & $0.65-5.51$ & 0.191 & 4.13 & $1.76-9.66$ & 0.001 \\
\hline
\end{tabular}

Abbreviations: ALL, acute lymphoblastic leukemia; CI, confidence interval; EFS, event-free survival; Ik6, Ikaros isoform 6; MRD, minimal residual disease; MSI2, Musashi-2; PB, peripheral blood; OS, overall survival; WBC, white blood cell.

of diagnosis [28]. We then compared the MSI2 mRNA levels between patients with $B C R / A B L 1$ and those without this fusion gene. However, no such difference was found. Our result is inconsistent with the previous conclusion about the existing correlation between MSI2 mRNA expression and BCR/ABL1 [13]. These controversial results about BCR/ABL1 and MSI2 mRNA levels may be caused by different sample compositions: Jaspal Kaeda and his colleagues used hematopoietic cell lines to perform their study, whereas we focused on BM samples from pediatric ALL patients. Additionally, as there were only 11 patients with $B C R / A B L 1$ (9\%) in our study, the relationship between MSI2 mRNA levels and BCR/ABL1 may be concealed more or less as a result of the small sample size.

Considering the above results, we were interested in demonstrating whether MSI2 mRNA levels had a prognostic significance for childhood ALL. In our group, patients with MSI2 mRNA overexpression had poorer overall survival rates than those in the low MSI2 mRNA group. Compared with the results for OS, no significant difference in EFS was found between the high MSI2 mRNA group and the low MSI2 mRNA group, respectively. Drug resistance, lower remission re-induction rates and the persistence of MRD are the features of refractory or recurrent leukemia [29-31]. As expected, patients in the high MSI2 mRNA group had lower CR rates. Besides, though not reached a significant difference, the rate of sensitive prednisone response in the high MSI2 mRNA group was lower than in the low MSI2 mRNA group. The MRD levels at the mid-course of induction (Day22 MRD), which have been proved to be a risk factor for ALL relapse in the previous study [15], were also collected and compared. However, no difference was found in Day 22 MRD levels between the two groups classified according to MSI2 mRNA levels.

We then analyzed the outcomes in patients with childhood ALL according to the IK6 mutation status and MSI2 mRNA levels. The results suggested that ALL patients in MSI2hiIK6+ group had inferior outcomes, either for OS, or for EFS compared to the patients of other three groups. Our finding implies that the combination of IK6 and MSI2 mRNA levels could be used to identify a group of patients with poor prognosis in childhood ALL.

In our multivariate analysis, after including most of the known clinical prognostic factors, MSI2 mRNA overexpression was still an independent predictor for inferior OS, but not for EFS in this cohort. Our finding is in accordance with previous studies conducted in AML patients and adults ALL patients suggesting the negative prognostic influence of high MSI2 based on mRNA and protein levels [5,10-12]. In addition, the other two genetic abnormalities, i.e. IK6 and $B C R /$ $A B L 1$, had also independently prognostic effects on OS and EFS, respectively, for the whole cohort of childhood ALL patients.

In conclusion, we have shown that MSI2 mRNA overexpression was signifiantly correlated with poor outcomes in pediatric ALL patients. In addition, we also confirmed that MSI2 mRNA levels were correlated with IK6 mutation status. However, there exist several limitations in the present study. Firstly, research design does not allow us to detect whether MSI2 act through other mechanisms except the NUMB pathway in leukemic cells, which have been implied in the previous studies $[5,7]$. Thereby, we cannot explain clearly how the high MSI2 mRNA levels affect outcomes in pediatric ALL patients. Furthermore, our study was conducted in the population with a relatively small sample size of Asian population. As the data on the prognostic impact of the MSI2 mRNA overexpression in childhood ALL patients are limited, further studies with largescale and different ethnic backgrounds are needed to confirm the prognostic significance of MSI2 in children with ALL.

Supplementary information is available in the online version of the paper.

Acknowledgments: This study was supported in part by grants from the National Natural Science Foundation of China (Nos: 30971283, 81170502, 81470304, 81300400, 81200386), Zhejiang Provincial Natural Science Foundation of China (Nos: LZ12H08001, 
Q12H080008), Leukemia Research Innovative Team of Zhejiang Province (No: 2011R50015) and Department of Health of Zhejiang Province of China (No: 2013KYA107).

\section{References}

[1] WOO JS, ALBERTI MO, TIRADO CA. Childhood B-acute lymphoblastic leukemia: a genetic update. Experimental hematology \& oncology 2014; 3: 16. http://dx.doi. org/10.1186/2162-3619-3-16

[2] MOORMAN AV. The clinical relevance of chromosomal and genomic abnormalities in B-cell precursor acute lymphoblastic leukaemia. Blood reviews 2012; 26: 123-135. http:// dx.doi.org/10.1016/j.blre.2012.01.001

[3] WHO Classification of Tumours of Haematopoietic and Lymphoid tissues Lyon: IARC 2008.

[4] PUI C-H, EVANS WE. Treatment of acute lymphoblastic leukemia. New England Journal of Medicine 2006; 354: 166-178. http://dx.doi.org/10.1056/NEJMra052603

[5] THOL F, WINSCHEL C, SONNTAG A-K, DAMM F, WAGNER K, et al.. Prognostic significance of expression levels of stem cell regulators MSI2 and NUMB in acute myeloid leukemia. Ann Hematol 2013; 92: 315-323. http://dx.doi. org/10.1007/s00277-012-1637-5

[6] ITO T, KWON HY, ZIMDAHL B, CONGDON KL, BLUM J, et al. Regulation of myeloid leukaemia by the cell-fate determinant Musashi. Nature 2010; 466: 765-768. http://dx.doi. org/10.1038/nature09171

[7] KHARAS MG, LENGNER CJ, AL-SHAHROUR F, BULLINGER L, BALL B, et al. Musashi-2 regulates normal hematopoiesis and promotes aggressive myeloid leukemia. Nature medicine 2010; 16: 903-908. http://dx.doi. org/10.1038/nm.2187

[8] WANG X-Y, PENALVA LO, YUAN H, LINNOILA RI, LU $\mathrm{J}$, et al. Musashi1 regulates breast tumor cell proliferation and is a prognostic indicator of poor survival. Molecular cancer 2010; 9: 221. http://dx.doi.org/10.1186/1476-45989-221

[9] ZHOU Y-H, HESS KR, RAJ VR, YU L, LIU L, et al. Establishment of prognostic models for astrocytic and oligodendroglial brain tumors with standardized quantification of marker gene expression and clinical variables. Biomarker insights 2010; 5: 153. http://dx.doi.org/10.4137/BMI.S6167

[10] BYERS RJ, CURRIE T, THOLOULI E, RODIG SJ, KUTOK JL. MSI2 protein expression predicts unfavorable outcome in acute myeloid leukemia. Blood 2011; 118: 2857-2867. http:// dx.doi.org/10.1182/blood-2011-04-346767

[11] ALY R, GHAZY H. Prognostic significance of MSI2 predicts unfavorable outcome in adult B-acute lymphoblastic leukemia. Int J Lab Hematol 2014.

[12] MU Q, WANG Y, CHEN B, QIAN W, MENG H, et al. High expression of Musashi-2 indicates poor prognosis in adult B-cell acute lymphoblastic leukemia. Leuk Res 2013; 37: 922-927. http://dx.doi.org/10.1016/j.leukres.2013.05.012

[13] KAEDA J, RINGEL F, OBERENDER C, MILLS K, QUINTARELLI C, et al. Upregulated MSI2 is associated with more aggressive leukemia. Leukemia \& lymphoma 2014: 1-28.
[14] SUBSPECIALTY GROUP OF HEMATOLOGY DISEASES T, SOCIETY OF PEDIATRICS CMA. Recommendations for diagnosis and treatment of acute lymphoblastic leukemia in childhood (3rd revised version). Zhonghua er ke za zhi. Chinese journal of pediatrics 2006; 44: 392.

[15] XU XJ, TANG YM, SHEN HQ, SONG H, YANG SL, et al. Day 22 of induction therapy is important for minimal residual disease assessment by flow cytometry in childhood acute lymphoblastic leukemia. Leuk Res 2012; 36: 1022-1027. http:// dx.doi.org/10.1016/j.leukres.2012.03.014

[16] SHEN H-Q, FENG J-H, TANG Y-M, SONG H, YANG S-L, et al. Absolute lymphocyte count is associated with minimal residual disease level in childhood B-cell precursor acute lymphoblastic leukemia. Leuk Res 2013; 37: 671-674. http:// dx.doi.org/10.1016/j.leukres.2013.02.002

[17] TANG Y, XU X, SONG H, YANG S, SHI S, et al. Long-term outcome of childhood acute lymphoblastic leukemia treated in China. Pediatr Blood Cancer 2008; 51: 380-386. http:// dx.doi.org/10.1002/pbc.21629

[18] BALDUS CD, BURMEISTER T, MARTUS P, SCHWARTZ S, GOKBUGET N, et al. High expression of the ETS transcription factor ERG predicts adverse outcome in acute T-lymphoblastic leukemia in adults. Journal of Clinical Oncology 2006; 24: 4714-4720. http://dx.doi.org/10.1200/JCO.2006.06.1580

[19] MARCUCCI G, BALDUS CD, RUPPERT AS, RADMACHER MD, MROZEK K, et al. Overexpression of the ETS-related gene, ERG, predicts a worse outcome in acute myeloid leukemia with normal karyotype: a Cancer and Leukemia Group B study. J Clin Oncol 2005; 23: 9234-9242. http://dx.doi.org/10.1200/JCO.2005.03.6137

[20] MULLIGHAN CG, MILLER CB, RADTKE I, PHILLIPS LA, DALTON J, et al. BCR-ABL1 lymphoblastic leukaemia is characterized by the deletion of Ikaros. Nature 2008; 453: 110-114. http://dx.doi.org/10.1038/nature06866

[21] GREAVES M. Childhood leukaemia. BMJ 2002; 324: $283-$ 287. http://dx.doi.org/10.1136/bmj.324.7332.283

[22] PUI C-H, CARROLL WL, MESHINCHI S, ARCECI RJ. Biology, risk stratification, and therapy of pediatric acute leukemias: an update. Journal of Clinical Oncology 2011; 29: 551-565. http://dx.doi.org/10.1200/JCO.2010.30.7405

[23] STANULLA M, SCHRAPPE M. Treatment of childhood acute lymphoblastic leukemia. 2009. Elsevier. p 52-63.

[24] YE AF, HAN YX, ZHANG SH, LI HY, CHEN CQ, et al. Expression of musashi-2 gene in leukemia stem cells from acute myeloid leukemia patients. Zhongguo Shi Yan Xue Ye Xue Za Zhi 2014; 22: 1235-1238.

[25] WANG L, HOWARTH A, CLARK R. Ikaros transcripts Ik6/10 and levels of full-length transcript are critical for chronic myeloid leukaemia blast crisis transformation. Leukemia 2014. http://dx.doi.org/10.1038/leu.2014.99

[26] KUIPER R, WAANDERS E, VAN DER VELDEN V, VAN REIJMERSDAL S, VENKATACHALAM R, et al. IKZF1 deletions predict relapse in uniformly treated pediatric precursor B-ALL. Leukemia 2010; 24: 1258-1264. http://dx.doi. org/10.1038/leu.2010.87

[27] MULLIGHAN CG, SU X, ZHANG J, RADTKE I, PHILLIPS LA, et al. Deletion of IKZF1 and prognosis in 
acute lymphoblastic leukemia. New England Journal of Medicine 2009; 360: 470-480. http://dx.doi.org/10.1056/ NEJMoa0808253

[28] CRIST W, CARROLL A, SHUSTER J, JACKSON J, HEAD $\mathrm{D}$, et al. Philadelphia chromosome positive childhood acute lymphoblastic leukemia: clinical and cytogenetic characteristics and treatment outcome. A Pediatric Oncology Group study. Blood 1990; 76: 489-494.

[29] BHATLA T, JONES CL, MEYER JA, VITANZA NA, RAETZ EA, et al. The biology of relapsed acute lymphoblastic leuke- mia: opportunities for therapeutic interventions. Journal of pediatric hematology/oncology 2014; 36: 413. http://dx.doi. org/10.1097/MPH.0000000000000179

[30] HONGO T, FUJII Y. In vitro chemosensitivity of lymphoblasts at relapse in childhood leukemia using the MTT assay. International journal of hematology 1991; 54: 219-230.

[31] KLUMPER E, PIETERS R, VEERMAN A, HUISMANS D, LOONEN A, et al. In vitro cellular drug resistance in children with relapsed/refractory acute lymphoblastic leukemia. Blood 1995; 86: 3861-3868. 


\section{Supplementary Information}

\section{Prognostic significance of the Musashi-2 (MSI2) gene in childhood acute lymphoblastic leukemia}

Division of Hematology-oncology, Children's Hospital of Zhejiang University School of Medicine, Key Laboratory of Reproductive Genetics (Zhejiang University), Ministry of Education, Yan-an Street, Hangzhou 310003, PR CHINA

*Correspondence: Y_M_TANG@zju.edu.cn

${ }^{*}$ Contributed equally to this work.

a

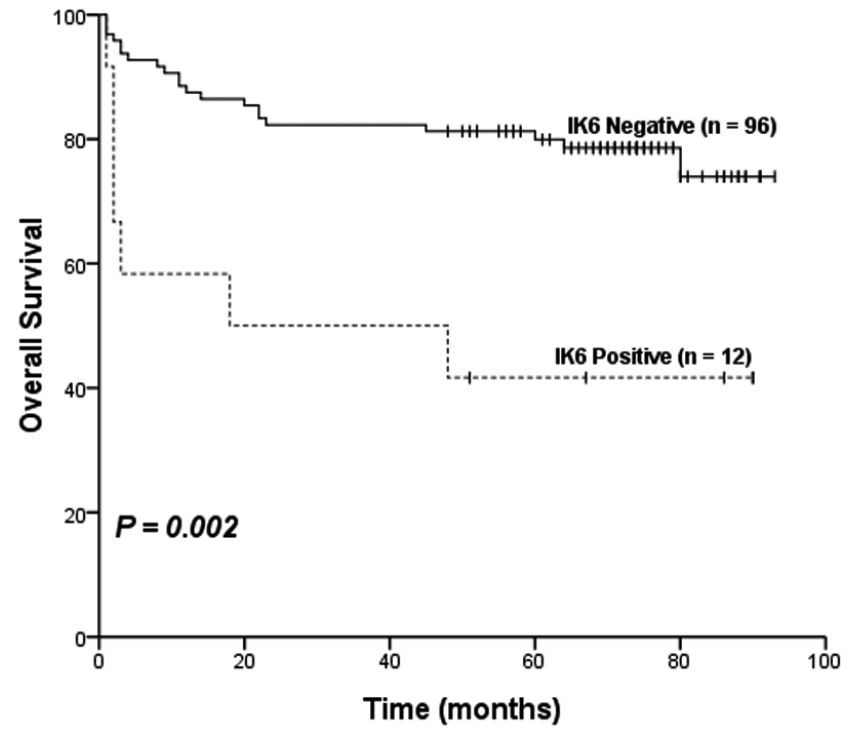

b

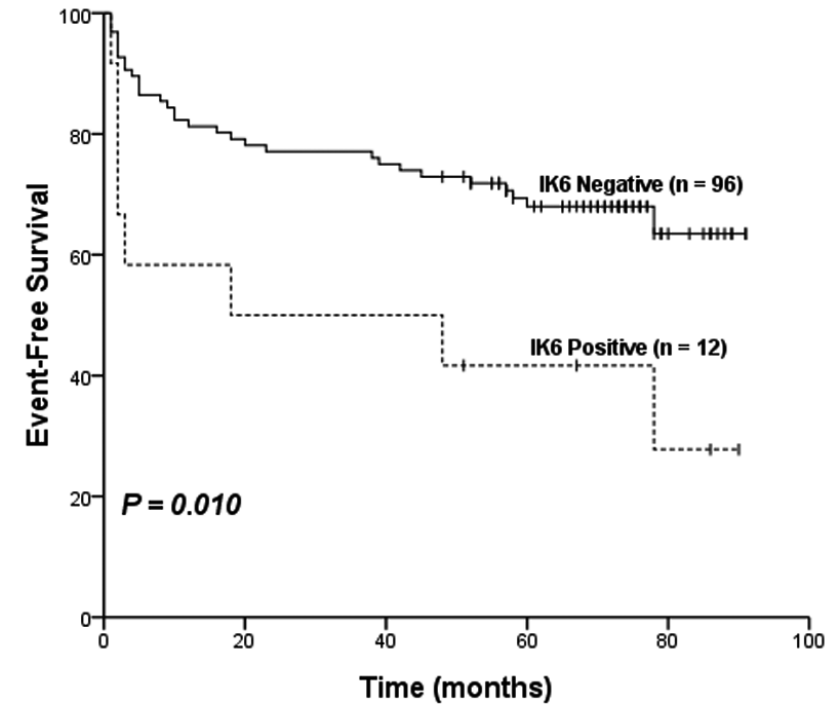

Supplemental Figure 1. Influence of IK6 on outcomes in childhood ALL patients. Patients with IK6 mutation had inferior OS (a) $(P=0.002)$ and EFS $(b)$ $(P=0.010)$. Kaplan-Meier analysis demonstrated that estimated 5-year OS rate for patients with IK6 mutation was $42 \%$, whereas the estimated 5-year OS rate in IK6 negative group was $80 \%$ (a). Similar results were also found in EFS between IK6 negative group and IK6 positive group $(b)(P=0.010)$. 
a

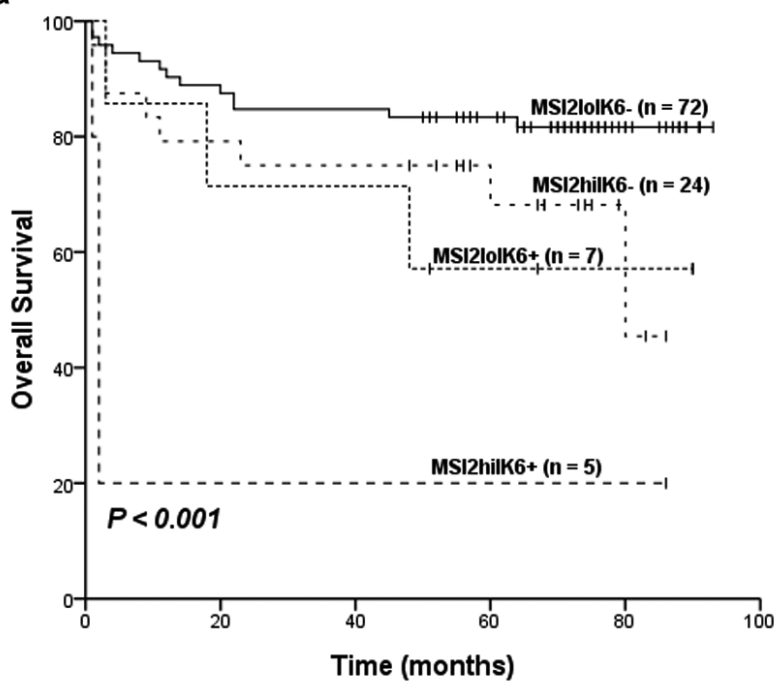

b

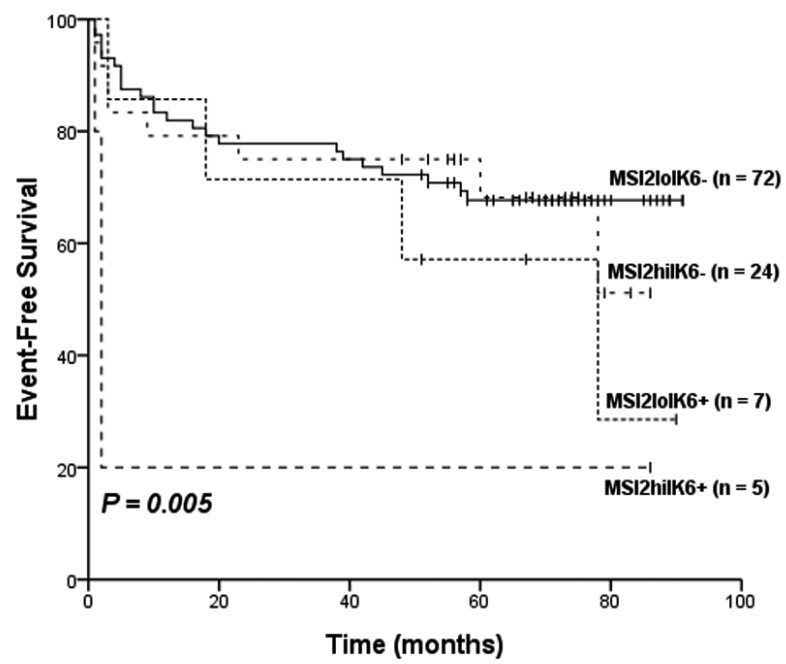

Supplemental Figure 2. Survival analysis according to the IK6 mutation status and MSI2 mRNA levels in childhood ALL patients. OS (a) $(P<0.001)$ and EFS (b) $(P=0.005)$ were different among patients in the four groups of MSI2hiIK6+, MSI2hiIK6-, MSI2loIK6+ and MSI2loIK6-.

Supplemental Table I. Characteristics of controls and patients

\begin{tabular}{lc}
\hline Controls & \\
Gender, Male/Female & $23 / 13$ \\
Age (years), median (range) & $6(1-14)$ \\
WBC count (x10 $/ \mathrm{L})$, median (range) & $8.43(4.23-11.7)$ \\
Patients & \\
Gender, Male/Female & $76 / 43$ \\
Age (years), median (range) & $6(1-14)$ \\
WBC count $\left(\mathrm{x} 10^{9} / \mathrm{L}\right)$, median (range) & $20.3(0.8-760)$ \\
\hline
\end{tabular}

Abbreviations: WBC, white blood cell 